\title{
Editorial
}

\section{Links between transforming growth factor- $\beta$ and canonical Wnt signaling yield new insights into breast cancer susceptibility, suppression and tumor heterogeneity}

\author{
1Department of Cell Biology, New York University School of Medicine, New York, USA
2Department of Dermatology, New York University School of Medicine, New York, USA
3Department of Pathology, New York University School of Medicine, New York, USA
}

Angela Incassati ${ }^{1,2}$, Alicia Pinderhughes ${ }^{1,2}$, Rachel Eelkema ${ }^{1,3}$ and Pamela Cowin ${ }^{1,2}$

Corresponding author: Pamela Cowin, cowinp01@nyumc.org

Published: 20 May 2009

Breast Cancer Research 2009, 11:103 (doi:10.1186/bcr2253)

This article is online at http://breast-cancer-research.com/content/11/3/103

(c) 2009 BioMed Central Ltd

See related research article by Roarty et al., http://breast-cancer-research.com/content/11/2/R19

\begin{abstract}
In a recent issue of Breast Cancer Research, investigators from the Serra laboratory describe a novel mechanism of transforming growth factor (TGF)- $\beta$ tumor suppression. Previously, the authors discovered that stromal TGF- $\beta$ signaled through $\mathrm{Wnt5}$ a to restrain pubertal ductal elongation and branching. Here, they show that inhibition of stromal TGF- $\beta$ signaling or Wnt5a loss leads to increased $\beta$-catenin transcriptional activity and reduced latency in mammary tumor models, with tumors displaying a higher proportion of progenitor cell markers. These findings reveal a novel intersection of two tumor suppressors with a potent oncogenic pathway and highlight the need for further study on the role played by canonical Wnt signaling in breast cancer susceptibility and subtype.
\end{abstract}

Rosa Serra has made important contributions to our understanding of the role played by transforming growth factor (TGF)- $\beta$ in breast throughout her career, and in a recent issue of Breast Cancer Research she describes a novel mechanism of TGF- $\beta$ tumor suppression [1]. Early work utilizing inducible dominant-negative type II receptors (metallothioneinlike promoter-TGF- $\beta$ dominant negative type II receptor [MT-DNIIR] and mouse mammary tumor virus long terminal repeat [MMTV]-DNIIR) to suppress TGF- $\beta$ signaling demonstrated that, despite its name, the function of TGF- $\beta$ within the mammary gland is one of cell type-specific restraint. TGF- $\beta$ signaling within stromal cells restrains lateral branching, and TGF- $\beta$ signaling within luminal epithelial cells restrains alveolar development [2,3]. Recently, the investigators from the Serra laboratory conducted a microarray analysis to identify genes that were affected by DNIIR expression, and in so doing they discovered a link between
TGF- $\beta$ and Wnt5a, which is a member of the Wnt family of secreted morphogens. They then elegantly combined genetics with transplantation approaches to establish that Wnt5a is essential for TGF- $\beta$-mediated restraint of ductal outgrowth and branching [4]. Multiple Wnts are expressed in breast, and their signaling through canonical ( $\beta$-catenin mediated) and noncanonical pathways is critical throughout mammary development [5]. Although deregulated canonical signaling induces murine mammary tumors and is implicated in human breast cancers, Wnt5a appears to act as a breast tumor suppressor $[6,7]$. This activity may be related to its propensity to signal through noncanonical pathways that, in many settings, antagonize canonical Wnt signaling [7].

Having demonstrated the physiologic function of the TGF- $\beta$ / Wnt5a pathway in the mammary gland, the authors next focused on its role in tumor suppression [1]. When crossed to MMTV-PyVmT or MMTV-neu transgenic models, MT-DNIIR and $\mathrm{Wnt5}^{-/}$mice developed tumors with increased proliferation and earlier onset. Wnt5a levels were decreased in DNIIR tumors, supporting the notion that TGF- $\beta$ regulates Wnt5a [1]. Whether Wnt5a expression can rescue the loss of tumor suppression exhibited by MT-DNIIR mice remains to be demonstrated. Nonetheless, the possibility that TGF- $\beta$ exerts its tumor suppressive effects through Wnt5a suggests a new route to therapeutically augment TGF- $\beta$ tumor suppressor function separately from its metastasis-promoting effects.

A second important observation in this study is that inhibition of TGF- $\beta$ or loss of Wnt5a increased canonical Wnt signaling. Previous studies in luminal cells show that TGF- $\beta$

MMTV = mouse mammary tumor virus long terminal repeat; MT-DNIIR = metallothionein-like promoter-TGF- $\beta$ dominant negative type II receptor; $\mathrm{TGF}=$ transforming growth factor . 
and canonical Wnt signaling produce opposite effects. For example, upregulation of the canonical Wnt pathway (MMTV$\beta$-catenin) or inhibition of TGF- $\beta$ signaling (MMTV-DNIIR) induces precocious alveologenesis $[2,8]$. In contrast, stromal MT-DNIIR or loss of epithelial Wnt5a results in several phenotypes that are similar to those produced by MMTVWnt1 (hyperbranching, increased vascularization, and stromal hypertrophy) $[3,9]$. The experiments conducted by Roarty and coworkers [1] establish the requirement for Wnt5a within mammary epithelial cells, but leave open the question of whether it targets luminal or basal cells. Another recent study has shown that MMTV-Wnt1 activates canonical signaling in a paracrine fashion exclusively within $\mathrm{K}_{14}{ }^{+}$cells [9]. Taken together, these findings suggest that $\mathrm{K}_{14} 4^{+}$cells are the most likely site of Wnt5a suppression of canonical signaling.

Several groups have shown that MMTV-Wnt1 expands cell populations expressing K14, Sca1, K6, CD24lo/49fhigh, and other profiles that have been associated with stem and early progenitor populations [9-13]. Roarty and coworkers [1] now show that inhibition of TGF- $\beta$ and Wnt5a loss result in the emergence of cells with similar characteristics. These findings suggest that TGF- $\beta$ and Wnt5a exert their tumor suppressive effects by antagonizing the canonical Wnt pathway and limiting the number of stem cells from which tumors may arise. What remains to be addressed is whether this occurs early in development to limit the tumor source, or later to slow tumor progression. Because MT-DNIIR is inducible, this can be experimentally addressed [3]. In support of the former scenario, upregulated canonical signaling and increased Sca1 expression are already present in Wnt5a $\mathrm{a}^{-/}$and DNIIR tissue, regardless of expression of the MMTV-PyVmT or MMTV-neu transgenes. This supports the concept that an early increase in stem cell number may itself be a major risk factor for cancer development, and that studies focusing on canonical Wnt signaling and the factors that regulate it, such as TGF- $\beta$ and Wnt5a, warrant further investigation.

On the other hand, the finding that tumors arising on DNIIR and $\mathrm{Wnt}_{5} \mathrm{a}^{-/}$genetic backgrounds showed higher rates of proliferation supports the possibility that TGF- $\beta$ and Wnt5a exert their suppressive effects by slowing tumor growth. These observations illuminate the fact that canonical Wnt signaling is critical for tumor maintenance and proliferation. Indeed, recent studies have demonstrated the therapeutic effectiveness of inhibiting canonical Wnt signaling in tumors initiated by diverse oncogenes. For example, both 7,12-dimethylbenz(a)anthracene/12-O-tetradecanoylphorbol-13-acetate ras-induced tumors and basaloid hamartomas resulting from Hedgehog pathway hyperactivity have been shown to regress completely upon blockade of the Wnt pathway $[14,15]$.

Finally, the studies reported by Roarty and coworkers [1] also show that genetic background may have as great an effect on breast cancer subtype as either the cancer cell of origin or the oncogenic stimulus. Their observations underscore the concept that genetic and environmental factors that affect canonical Wnt signaling may influence tumor phenotype. In sum, the Serra laboratory investigators have discovered a new mechanism of TGF- $\beta$-mediated tumor suppression through regulation of $\beta$-catenin that has exciting implications for our understanding of tumor susceptibility and heterogeneity.

\section{Competing interests}

The authors declare that they have no competing interests.

\section{References}

1. Roarty K, Baxley SE, Crowley MR, Frost AR, Serra R: Loss of TGF- $\beta$ or Wnt5a results in an increase in Wnt/ $\beta$-catenin activity and redirects mammary tumor phenotype. Breast Cancer Res 2009, 11:R19.

2. Gorska AE, Joseph H, Derynck R, Moses HL, Serra R: Dominantnegative interference of the transforming growth factor beta type II receptor in mammary gland epithelium results in alveolar hyperplasia and differentiation in virgin mice. Cell Growth Differ 1998, 9:229-238.

3. Joseph H, Gorska AE, Sohn P, Moses HL, Serra R: Overexpression of a kinase-deficient transforming growth factor-beta type II receptor in mouse mammary stroma results in increased epithelial branching. Mol Biol Cell 1999, 10:1221-1234.

4. Roarty K, Serra R: Wnt5a is required for proper mammary gland development and TGF-beta-mediated inhibition of ductal growth. Development 2007, 134:3929-3939.

5. Hatsell S, Rowlands TR, Hiremath M, Cowin P: $\beta$-Catenin and Tcfs in mammary development and cancer . J Mammary Gland Biol Neoplasia 2003, 8:145-158.

6. Cowin P, Rowlands TM, Hatsell SJ: Cadherins and catenins in breast cancer. Curr Opin Cell Biol 2005, 17:499-508.

7. Jonsson M, Dejmek J, Bendahl PO, Andersson T: Loss of Wnt-5a protein is associated with early relapse in invasive ductal breast carcinomas. Cancer Res 2002, 62:409-416.

8. Imbert $A$, Eelkema $R$, Jordan $S$, Feiner $H$, Cowin $P: \Delta N 89 \beta$-catenin induces precocious development, differentiation, and neoplasia in mammary gland. J Cell Biology 2001, 153:555-568.

9. Teissedre B, Pinderhughes A, Incassati A, Hatsell SJ, Hiremath $M$, Cowin P: MMTV-Wnt1 and -DeltaN89beta-catenin induce canonical signaling in distinct progenitors and differentially activate Hedgehog signaling within mammary tumors. PLoS ONE 2009, 4:e4537.

10. Li Y, Welm B, Podsypanina K, Huang S, Chamorro M, Zhang X, Rowlands T, Egeblad M, Cowin P, Werb Z, Tan LK, Rosen JM, Varmus HE: Evidence that transgenes encoding components of the Wnt signaling pathway preferentially induce mammary cancers from progenitor cells. Proc Natl Acad Sci USA 2003, 100:15853-15858.

11. Liu BY, Kim YC, Leatherberry V, Cowin P, Alexander CM: Mammary gland development requires syndecan-1 to create a beta-catenin/TCF-responsive mammary epithelial subpopulation. Oncogene 2003, 22:9243-9253.

12. Liu BY, McDermott SP, Khwaja SS, Alexander CM: The transforming activity of Wnt effectors correlates with their ability to induce the accumulation of mammary progenitor cells. Proc Natl Acad Sci USA 2004, 101:4158-4163.

13. Shackleton M, Vaillant F, Simpson KJ, Stingl J, Smyth GK, AsselinLabat ML, Wu L, Lindeman GJ, Visvader JE: Generation of a functional mammary gland from a single stem cell. Nature 2006, 439:84-88.

14. Malanchi I, Peinado H, Kassen D, Hussenet T, Metzger D, Chambon P, Huber M, Hohl D, Cano A, Birchmeier W, Huelsken $\mathrm{J}$ : Cutaneous cancer stem cell maintenance is dependent on beta-catenin signalling. Nature 2008, 452:650-653.

15. Yang SH, Andl T, Grachtchouk V, Wang A, Liu J, Syu LJ, Ferris J, Wang TS, Glick AB, Millar SE, Dlugosz AA: Pathological responses to oncogenic Hedgehog signaling in skin are dependent on canonical Wnt/ $\beta$-catenin signaling. Nature Genetics 2008, 40:1130-1135. 